
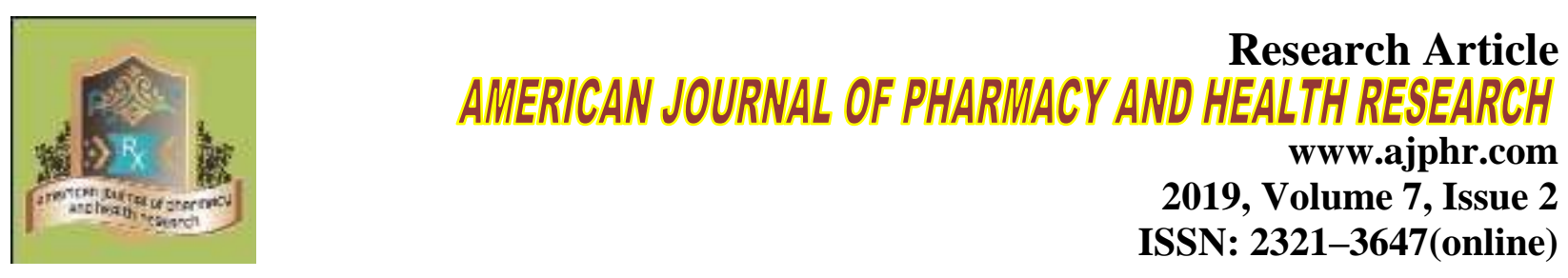

\title{
A Study on Therapeutic Evaluation of Various Antibiotics in Lower Respiratory Tract Infections in Adult Patients
}

\author{
G.Y. Srawan Kumar*1, D.R. Brahma Reddy ${ }^{2}$, D. Sudeena ${ }^{3}$, D. Nagarjuna ${ }^{4}$, S. Neelima ${ }^{4}$, T. \\ Kalyani $^{4}$, \\ 1. Department of Pharmaceutics, Associate professor, NIPS, Sattenapalli, Guntur. \\ 2. Department of Phytochemistry, Professor, NIPS, Sattenapalli, Guntur. \\ 3. Department of Pulmonology, Superintendent, Government fever hospital, Guntur. \\ 4. Pharm D $5^{\text {TH }}$ year, NIPS, Sattenapalli, Guntur.
}

\begin{abstract}
Lower respiratory tract infections (LRTIs) are among the most common infectious disease of humans worldwide and continue to be a major cause of morbidity. The overuse and misuse of antibiotics have been related to the growing emergence of bacterial resistance, increased incidence of adverse effects and prolonged hospitalization. This article focuses on bacterial infections, which includes the larynx, trachea, bronchi, and lung parenchyma. The main objective of this study is Therapeutic evaluation of various antibiotics in LRTI, and to study the demographic profile of patients, co-morbid conditions and clinical presentation of patients diagnosed with LRT infections. We conducted a single centre, prospective observational study by selecting patients who are diagnosed to have LRTI, patient case sheets were reviewed for antibiotics, co-morbid conditions, chest x-ray reports and different lab parameters in adults who are above 18 years prescribed at Government Fever Hospital, Guntur. A total of 335 patient case sheets were reviewed in the present study during the study period. In this study we observe that the most frequently prescribed antibiotics are higher percentage of patients using Cephalosporins (51.14\%) followed by Macrolides (17.09\%), Metronidazole (12.58\%), Penicillin's (7.66\%), Aminoglycosides (3.41\%), Doxycycline (3.41\%), Fluoroquinolones (3.27\%), Carbapenems $(1.30 \%)$ and other classes of drugs. This study concludes that LRTI usually causes minor illness, but may result in significant morbidity and mortality. Better lay and professional awareness of the often prolonged course of LRTI may improve understanding and appropriate use of antibiotics. Health care professionals are increase the awareness for improving quality of life in critically ill LRT infectious patients and preventing further complications.

Keywords: Respiratory tract, Therapeutic evaluation, Co-morbid conditions, Chest x-ray, Health care professionals, Hospitalization.
\end{abstract}

*Corresponding Author Email: damarlanagarjuna83@gmail.com

Received 07 February 2019, Accepted 13 February 2019

Please cite this article as: Srawan GY et al., A Study on Therapeutic Evaluation of Various Antibiotics in Lower Respiratory Tract Infections in Adult Patients. American Journal of Pharmacy \& Health

Research 2019. 


\section{INTRODUCTION}

Respiratory tract infections remain the major cause of morbidity from acute illness and most likely represent the single most common reason patients seek medical attention. This project focuses on bacterial infections involving the lower respiratory tract, which includes the larynx trachea bronchi and lung parenchyma. Most common bacterial infections involving the lower respiratory tract are bronchitis and pneumonia. Lower respiratory tract infections in children and adults most commonly result from either viral or bacterial invasion of lung parenchyma.

\section{Types of Lrti diseases:}

Lower respiratory tract infections are classified on the basis of the anatomical region infected:

BRONCHITIS: It refers to the onset of productive cough in a patient with no history of chronic obstructive pulmonary disease and no evidence of pneumonia. It is an inflammatory condition of Bronchi in the Lungs. The inflammatory process does not extend to the alveoli. Bronchitis frequently is classified acute or chronic. Acute bronchitis occurs in individuals of all ages, whereas chronic bronchitis primarily affects in adults ${ }^{(1)}$.

BRONCHIOLITIS: Bronchiolitis is a common lung infection. It causes inflammation and congestion in the small airways (bronchioles) of the lung. It is always caused by a virus. Typically, the peak time for bronchiolitis is during the winter months ${ }^{(2)}$.

COPD is a leading cause of morbidity and mortality worldwide. COPD is a disease state characterized by airflow limitation that is not fully reversible. Two principal conditions include;

- Chronic bronchitis: chronic or recurrent excess mucus secretion with cough that occurs on most days for at least 3 months of the year for at least 2 consecutive years. ${ }^{(3)}$

- Emphysema: abnormal, permanent enlargement of the airspaces distal to the terminal bronchioles, accompanied by destruction of their walls, without fibrosis.

PNEUMONIA: Pneumonia is an infection of lungs affecting primarily the small air sacs known as alveoli, distal airways and interstitium of lungs ${ }^{(4)}$. It is usually caused by viruses or bacteria and less commonly by other micro-organisms, certain medications and conditions like autoimmune diseases $^{(5)}$. The alveoli fill with fluid or pus, making it difficult to breath. Pneumonia is an infection in one or both lungs. Bacterial pneumonia is the most common type in adults (Streptococcus pneumonia) ${ }^{(6)}$. The disease may be classified by where it was acquired with community, hospital or health care associated pneumoniae. Pneumonia can be prevented by using some vaccines. 
Pulmonary Tuberculosis is a bacterial disease spread from one person to another principally by air bone transmission. The causal agent is Mycobacterium Tuberculosis. Tuberculosis can affect any organ in the body. Pulmonary Tuberculosis is the most frequent site of involvement; extra pulmonary tuberculosis is less frequent. Only pulmonary tuberculosis is infectious. ${ }^{(7)}$ The most frequent form of presentation of tuberculosis is disease that affects the lungs (pulmonary tuberculosis), while less frequent forms may affects any part of the body (extra pulmonary tuberculosis).

\section{MATERIALS AND METHOD}

\section{Study design:}

The study was conducted at Government Fever Hospital, Guntur for a period of 6 months. We recorded clinical data of all lower respiratory tract infectious patients for the therapeutic evaluation of various antibiotics.

\section{Study criteria:}

\section{Inclusion criteria:}

All adult in-patients of age $\geq 18$ years diagnosed with lower respiratory tract infections.

Patients who are willing to participate in the study.

\section{Exclusion criteria:}

Below 18 years of age and pregnant women. Patients who are not willing to participate in the study.

Ethical Considerations: Ethical committee approval was taken before initiation of the work.

Protocol Number: NIPS/PROTOCOL/01/2018.

\section{Study method:}

Study was conducted by selecting patients who are diagnosed to have lower respiratory tract infections. As pulmonary tuberculosis is the most common reason for hospitalization so priority has been given to pulmonary tuberculosis rather than respiratory tract infections in general.

Data were reviewed from patient case sheets for therapeutic evaluation of various antibiotics, Patients demographic details, Past medical history, Past medication history, Social history, Family history, Chief complaints, co-morbid conditions, Laboratory investigations such as complete blood picture, chest x-ray, sputum testing, pleural fluid, Bronchoscopy. A total of 335 patients were enrolled and their clinical data were collected and evaluated based on their usage of drugs. 


\section{RESULTS AND DISCUSSION}

In our study, among 335 patients, 220 (65.67\%) were Males and 115 (34.32\%) were Females.

Table 1: Gender Distribution

\begin{tabular}{llll}
\hline S.No & Gender & No. of Patients & Percentage \\
\hline 1. & Male & 220 & $65.67 \%$ \\
2. & Female & 115 & $34.32 \%$ \\
Total & & 335 & \\
\hline
\end{tabular}

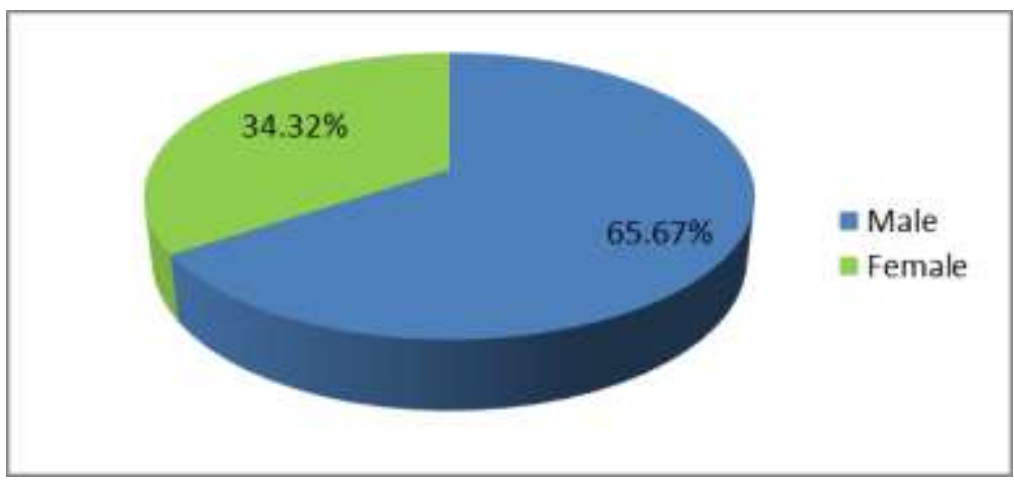

Figure 1: Gender Distribution of Patients

Table 2: Age Distribution with Gender

\begin{tabular}{lllllll}
\hline S.NO & Age Group & No. of patients & Males & Percentage & Females & Percentage \\
\hline 1. & $19-40$ & $107(31.94 \%)$ & 55 & $16.41 \%$ & 52 & $15.52 \%$ \\
2. & $41-65$ & $183(54.62 \%)$ & 133 & $39.70 \%$ & 50 & $14.92 \%$ \\
3. & $>65$ & $45(13.43 \%)$ & 32 & $9.55 \%$ & 13 & $3.88 \%$ \\
\hline
\end{tabular}

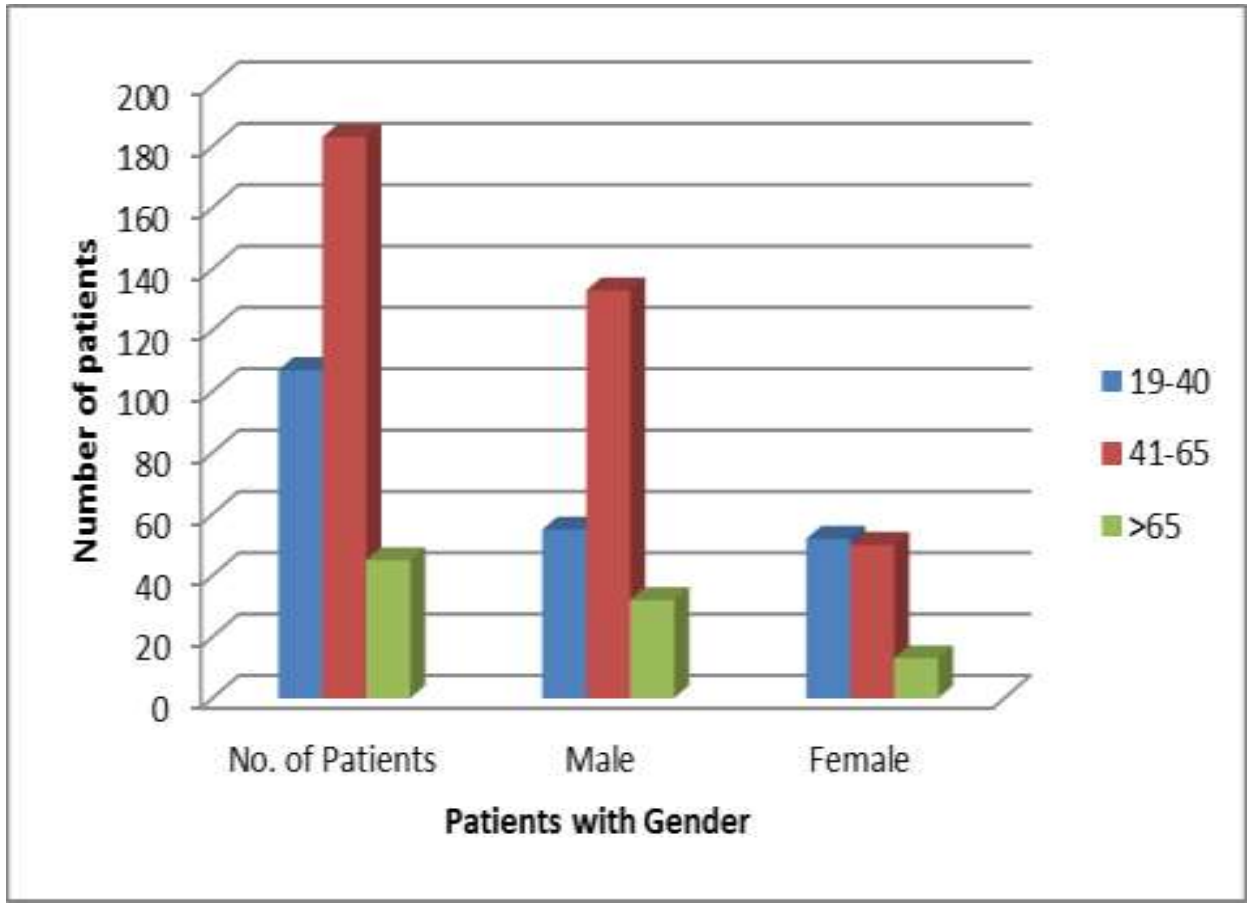

Figure 2: Bar diagram showing age with gender distribution of study population 
Table 3: Clinical presentation of Patients

\begin{tabular}{llll}
\hline S.NO & Symptoms & No. of Patients & Percentage \\
\hline 1. & SOB & 265 & $33.3 \%$ \\
2. & Cough & 248 & $31.2 \%$ \\
3. & Fever & 148 & $18.6 \%$ \\
4. & Chest pain & 75 & $9.4 \%$ \\
5. & Hemoptysis & 36 & $4.5 \%$ \\
6. & Others & 18 & $2.2 \%$ \\
\hline
\end{tabular}

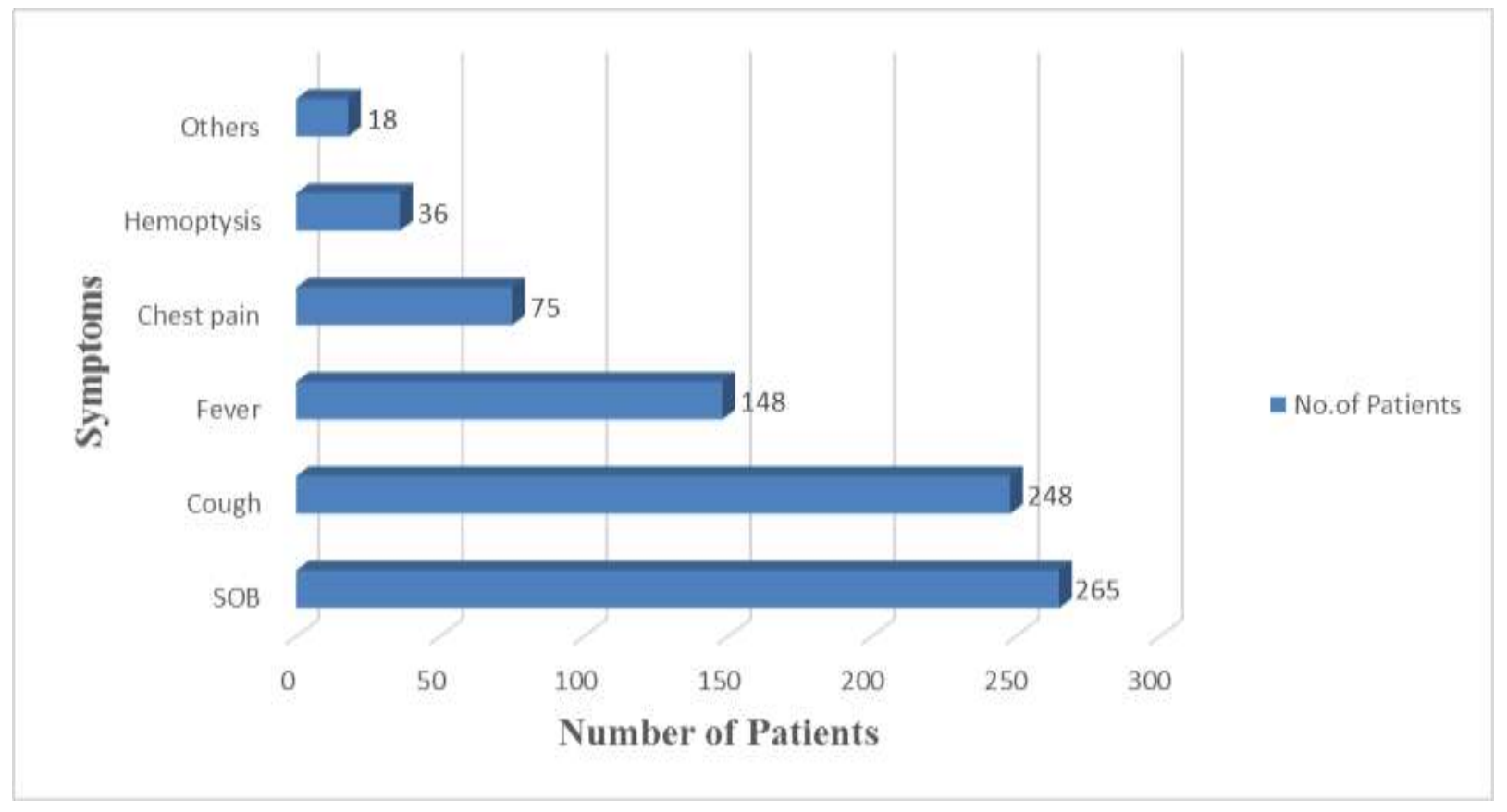

Figure 3: Clinical presentation of Patients

In a majority of patients (42\%) the Right lobe of the lung was involved

Table 4: Lobar involvement based on chest $x$-ray

\begin{tabular}{llll}
\hline S. No & $\begin{array}{l}\text { Chest x-ray- } \\
\text { Lobar involvement }\end{array}$ & No. of patients & Percentage \\
\hline 1. & Bilobar & 122 & $36.4 \%$ \\
2. & Right lobe & 141 & $42 \%$ \\
3. & Left lobe & 62 & $18.5 \%$ \\
4. & Normal & 10 & $2.9 \%$ \\
\hline
\end{tabular}




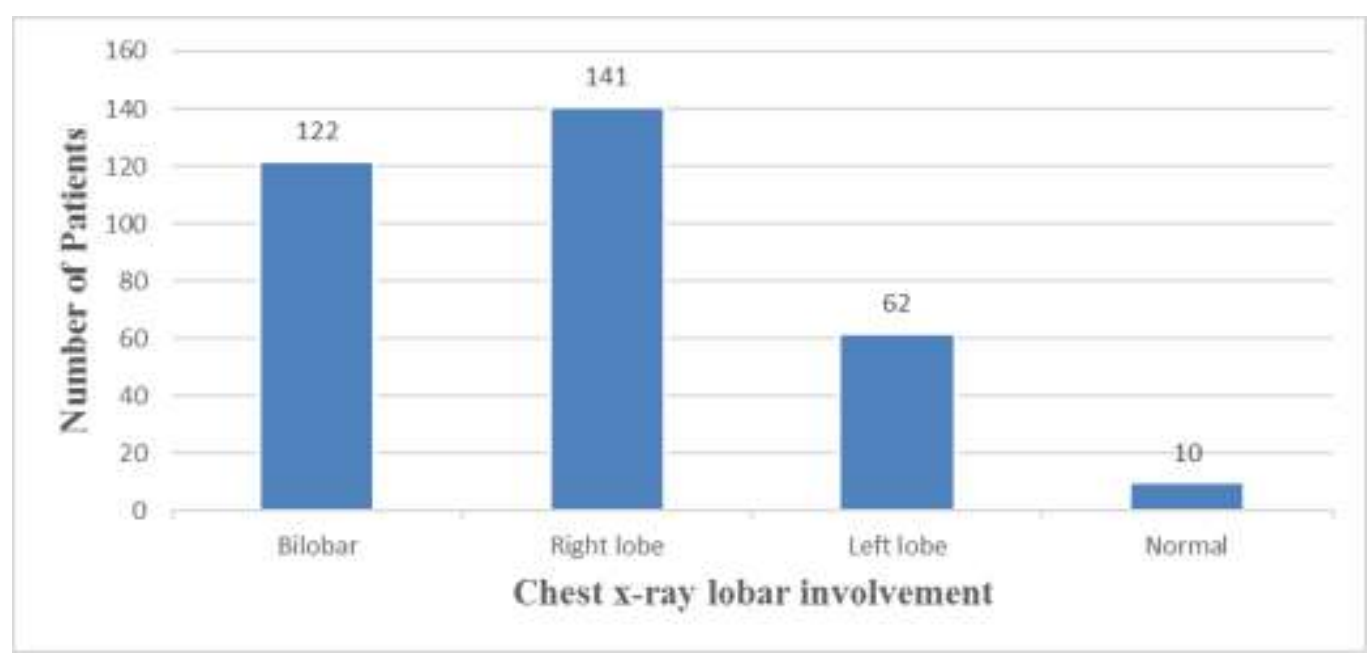

Figure 4: Lobar involvement based on chest $x-$ ray

Table 5: Sources of sample specimen

\begin{tabular}{lll}
\hline Sample & Sputum & Pleural fluid \\
\hline No of patients $(n=335)$ & 296 & 39 \\
\hline
\end{tabular}

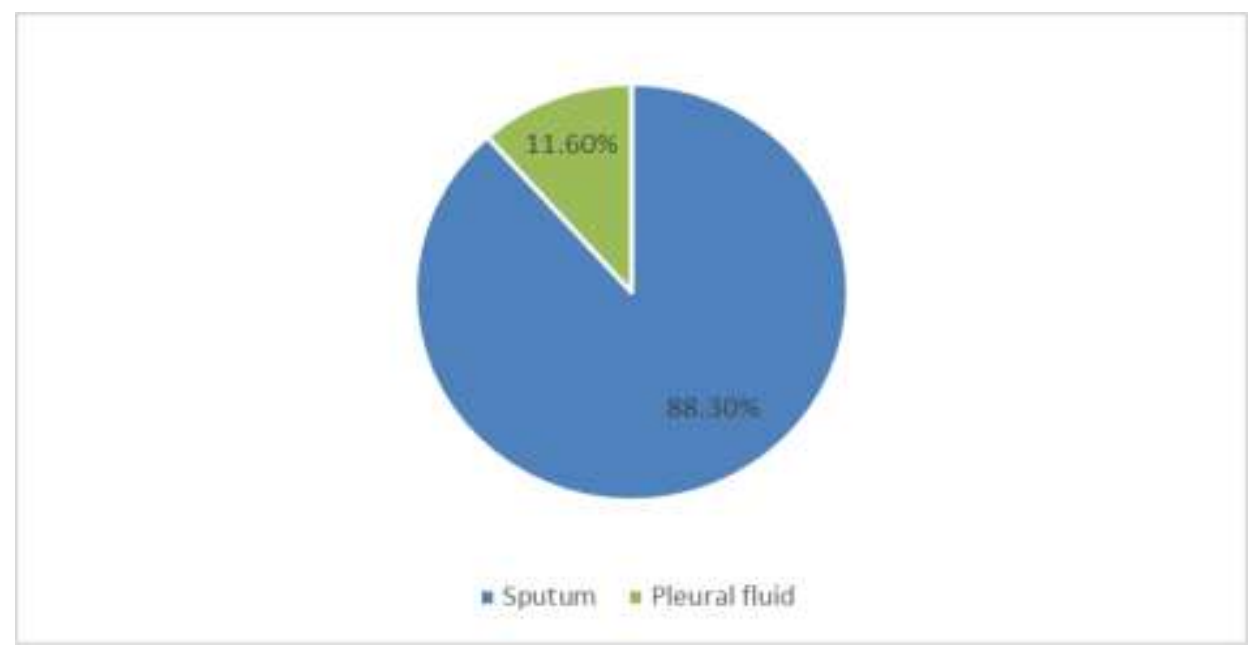

Figure 5: Sources of sample specimen

In our study population the total number of cases are 335, The highest number of cases observed were Pulmonary Tuberculosis are 153 patients (45.67\%), followed by COPD are 87 patients (25.9\%), Pneumonia are 42 patients (12.53\%), Pleural effusion cases are 39 patients (11.64\%), and Bronchiectasis cases are 14 patients (4.17\%).

Table 6: Types of Diseases:

\begin{tabular}{llll}
\hline S.No. & Types of infections & No. of patients effected & Percentage \\
\hline 1 & Pulmonary Tuberculosis & 153 & $45.67 \%$ \\
2 & Pneumonia & 42 & $12.53 \%$ \\
3 & Bronchiectasis & 14 & $4.17 \%$ \\
4 & COPD & 87 & $25.9 \%$ \\
5 & Pleural Effusion & 39 & $11.64 \%$ \\
\hline
\end{tabular}




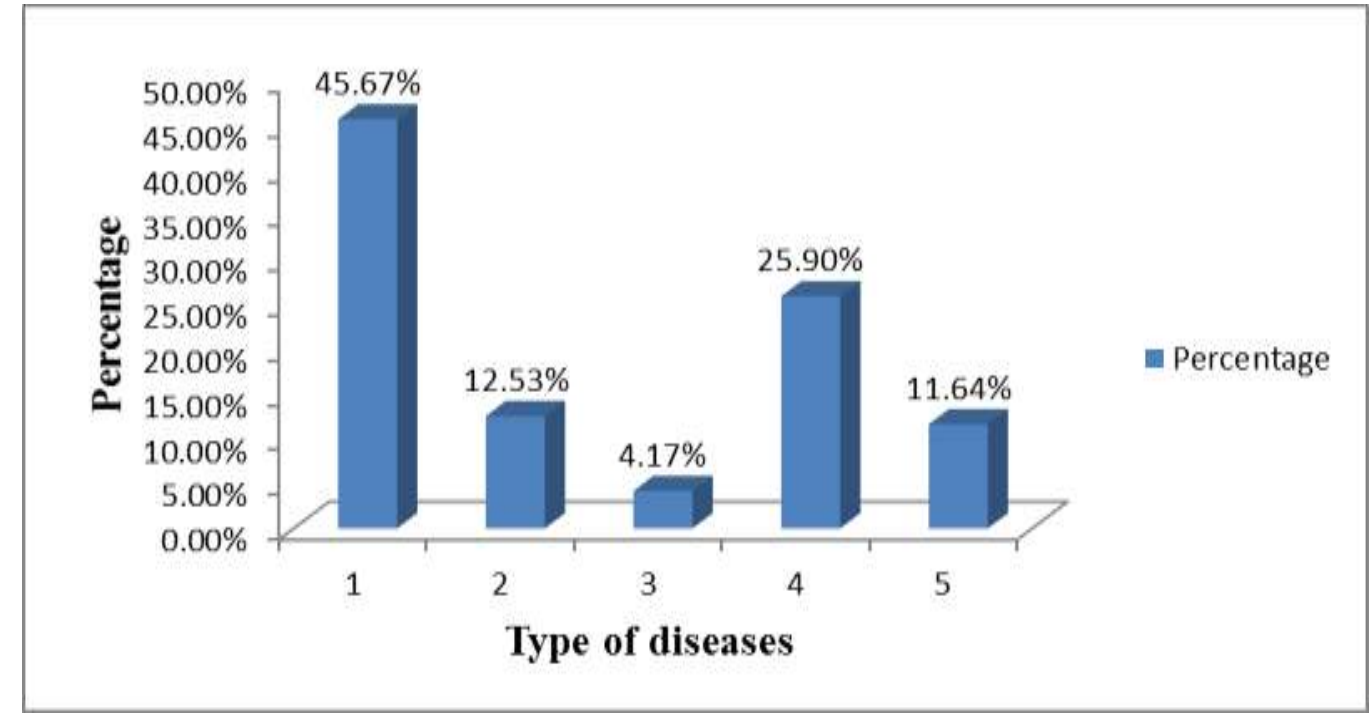

Figure 6: Bar diagram showing Types of diseases of study population

\section{Life Style of the Study Population:}

Life style of the study population are listed in the below table. The results revealed that $29.55 \%$ of patients were having habit of both smoking and alcohol, $11.04 \%$ of patients were having habit of smoking alone, 5.97\% of patients were having habit of alcohol alone, 53.43\% of study population were found to be having none of these habits.

\section{Table 7: Life style of study population}

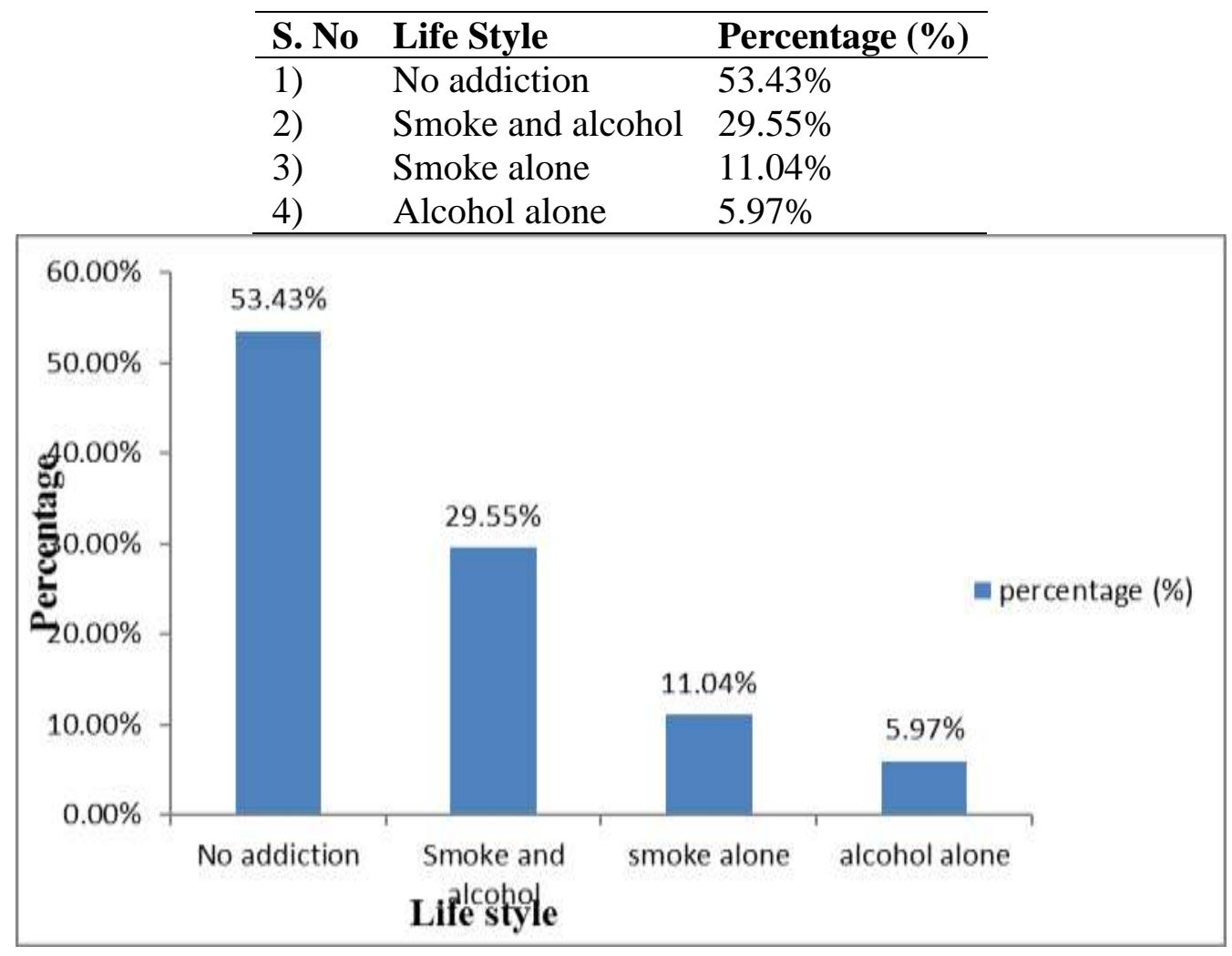

Figure 7: Bar diagram showing life style of the study population 
Table 8: Co-Morbid Conditions:

\begin{tabular}{llll}
\hline S.No & Co-morbid conditions & Number $(\mathbf{n = 3 3 5 )}$ & Percentage (\%) \\
\hline 1) & HIV & 45 & $13.43 \%$ \\
$2)$ & Hypertension (HTN) & 25 & $7.46 \%$ \\
$3)$ & Diabetes mellitus (DM) & 27 & $8.05 \%$ \\
$4)$ & Asthma & 14 & $4.17 \%$ \\
$5)$ & Other comorbidities & 12 & $3.58 \%$ \\
$6)$ & No co-morbidities observed & 212 & $63.28 \%$ \\
\hline
\end{tabular}

The co-morbidities of study population are given in the above table. The results revealed that 13.43\% were HIV, $7.46 \%$ were Hypertension, $8.05 \%$ were Diabetes Mellitus, $4.17 \%$ were Asthma, 3.58\% were Other comorbidities, and 63.28\% were No comorbidities observed.

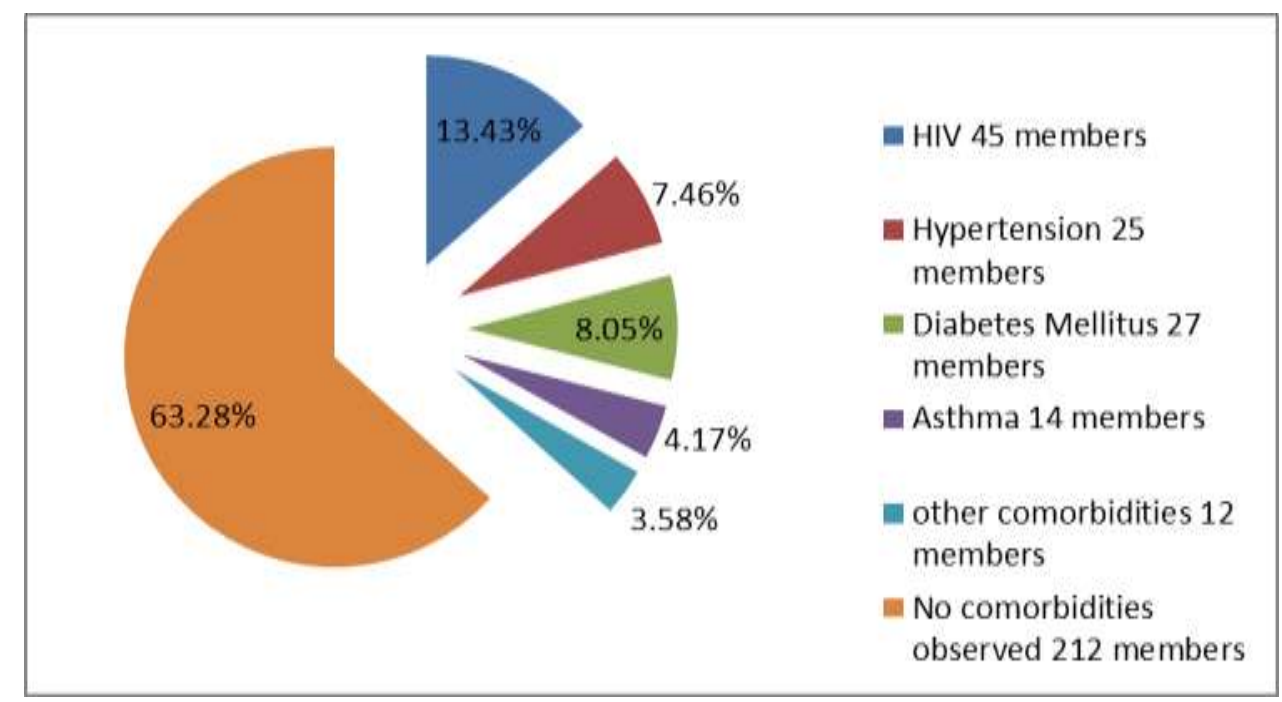

Figure 8: Pie diagram showing co-morbidities of study population

Table 9:List of antibiotics used

\begin{tabular}{lll}
\hline Name of the Antibiotic & No. of patients used & Percentage \\
\hline Ceftazidime & 14 & 1.91 \\
Metronidazole & 92 & 12.58 \\
Ceftriaxone & 248 & 33.92 \\
Cefixime & 102 & 13.95 \\
Azithromycin & 125 & 17.09 \\
Amoxiclav & 56 & 7.66 \\
(Amoxicillin + Clavulanic Acid) & & \\
Ciprofloxacin & 13 & 1.77 \\
Doxycycline & 25 & 3.41 \\
Cefotaxime & 10 & 1.36 \\
Amikacin & 14 & 1.91 \\
Meropenem & 10 & 1.30 \\
Kanamycin & 11 & 1.50 \\
Moxifloxacin & 11 & 1.50 \\
\hline
\end{tabular}




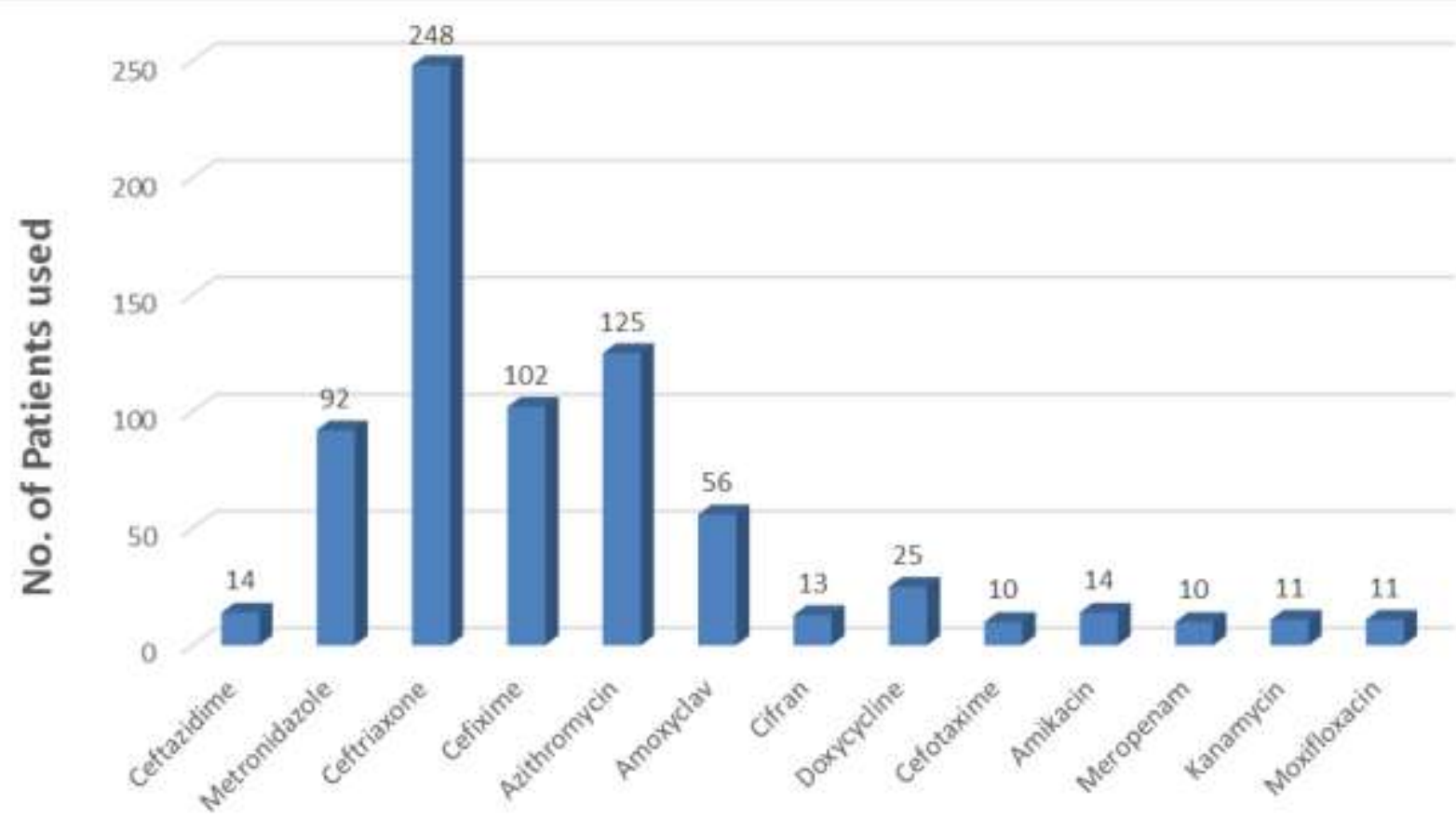

Antibiotics

Figure 9: Bar diagram showing list of antibiotics used by study population

Table 10: Prescriptions of antibiotics by classes

\begin{tabular}{|c|c|c|c|}
\hline \multirow{2}{*}{ Beta lactams } & \multicolumn{2}{|l|}{ Antibiotics } & \multirow{2}{*}{$\begin{array}{l}\text { Percentage } \\
7.66 \%\end{array}$} \\
\hline & Penicillins & Amoxiclav & \\
\hline & Cephalosporins & Ceftriaxone & $51.14 \%$ \\
\hline & & Cefixime & \\
\hline & & Ceftazidime & \\
\hline & & Cefotaxime & \\
\hline & Carbapenems & Meropenem & $1.30 \%$ \\
\hline \multicolumn{2}{|l|}{ Macrolides } & Azithromycin & $17.09 \%$ \\
\hline \multirow{2}{*}{\multicolumn{2}{|c|}{ Fluoroquinolones }} & Ciprofloxacin & $3.27 \%$ \\
\hline & & Moxifloxacin & \\
\hline \multirow{2}{*}{\multicolumn{2}{|c|}{ Aminoglycosides }} & Amikacin & $3.41 \%$ \\
\hline & & Kanamycin & \\
\hline \multirow[t]{2}{*}{ Others } & Tetracycline & Doxycycline & $3.41 \%$ \\
\hline & Nitroimidazoles & Metronidazole & $12.58 \%$ \\
\hline
\end{tabular}




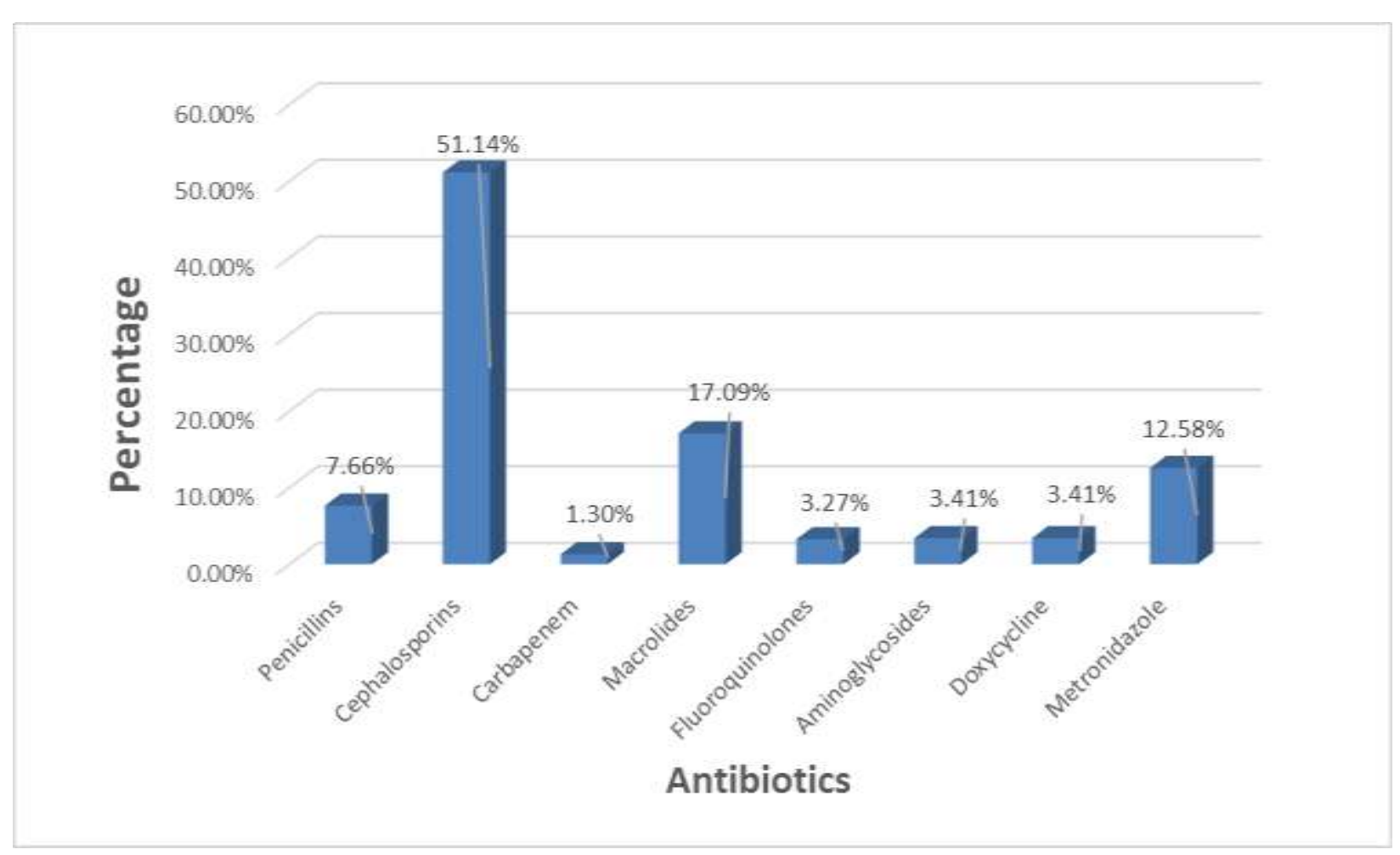

Figure 10: Prescriptions of antibiotics by classes

In our study 335 patient case sheets were reviewed, among them 153 patients are diagnosed with Pulmonary Tuberculosis .

In pulmonary tuberculosis, following Revised National Tuberculosis Control Programme (RNTCP) Guidelines based on the WHO for PTB control in Hospital.

Table 11: Pulmonary Tuberculosis Drugs

\begin{tabular}{|c|c|c|}
\hline $\begin{array}{ll}\text { Category } \\
\text { Treatment }\end{array}$ & Name of the drug & $\begin{array}{l}\text { No of } \\
\text { patients used }\end{array}$ \\
\hline Category I & $\begin{array}{l}\text { Isoniazid + Ethambutol } \\
\text { Isoniazid + Rifampicin } \\
\text { Rifampicin + Isoniazid + Ethambutol } \\
\text { AKT-4 (Rifampicin + Isoniazid + } \\
\text { Pyrazinamide + Ethambutol) }\end{array}$ & 153 \\
\hline Category II & $\begin{array}{l}\text { Rifampicin + Isoniazid + Pyrazinamide } \\
+ \text { Ethambutol + Streptomycin }\end{array}$ & \\
\hline
\end{tabular}

\section{DISCUSSION}

- Antibiotics continue to be widely prescribed for patients presenting with LRTI. Recommendations have been published advising against their use on the basis of increasing antimicrobial resistance in respiratory pathogens and lack of proven efficacy. A critical analysis of the published evidence for effectiveness of antibiotics reveals however a surprising paucity of data. For such a common, important and controversial 
area the studies informing evidence-based decision making are few, disparate and underpowered. ${ }^{(8)}$

- Trends favoring improved outcomes were seen for these measures of efficacy, but statistical significance was not reached. A non-significant trends towards side effects was seen in the treatment group. The antibiotics were unlikely to alter the course of illness in most adult patients. ${ }^{(9)}$

- The primary goal of this study was to ascertain the usage of antibiotics in lower respiratory tract infections in Government fever hospital, Guntur.

- In this study titled a total of 335 patients charts were reviewed, Out of 335 cases Males were 220 members (65.67\%) and Females were 115 members (34.32\%) as shown in fig 1.

- Higher percentage of the cases belonged to the age group of 41-65 are 54.62\%, as it is known that risk of LRTIs is significantly higher in this age group. Followed by age group $19-40$ are $31.94 \%$ and $>65$ age group effects $13.43 \%$ of patients in our study as shown in fig 2.

- Among the Signs and Symptoms of LRTIs maximum number of patients presented with Shortness of breath (33.3\%) followed by Cough (31.2\%), Fever (18.6\%), Chest pain (9.4\%), Hemoptysis (4.5\%) and Others are (2.2\%) as shown in fig 3.

- In our study chest x-ray of the patients showed involvement of right lobe in majority cases 141 patients (42\%) followed by bilobar involvement in 122 patients (36.4\%), left lobe in 62 patients $(18.5 \%)$, chest $x$-ray was found to be normal in 10 patients $(2.9 \%)$ as shown in fig 4.

- Sputum was the most common etiological source of organism isolation obtained from 296 patients (88.30\%) followed by Pleural fluid 39 patients (11.60\%) as shown in fig 5.

- LRTIs shows the results of various types of LRTIs that patients were effected in our study are Pulmonary Tuberculosis (TB) are 153 members (45.67\%) and COPD are 87 members (25.9\%) and Pneumonia are 42 members (12.53\%) and Pleural effusion are 39 members (11.64\%) and Bronchiectasis are 14 members (4.17\%) as shown in fig 6.

- In our study, 335 patients life style were revealed that $29.55 \%$ were found to having habit of both smoking and alcohol drinking, 11.04\% were found to be habit of smoking alone, $5.97 \%$ were found to be habit of alcohol drinking alone, and $53.43 \%$ of patients were found to be having none of these habits (No-addiction) as shown in fig 7. 
- The co-morbidities of the case studies revealed that $13.43 \%$ are HIV patients, $8.5 \%$ are Diabetes mellitus(DM), $7.46 \%$ are Hypertensive patients(HTN), 4.17\% are Asthma patients, $3.58 \%$ are other co-morbidities, and No co-morbidities observed were $63.28 \%$ as shown in fig 8.

- The results revealed that Therapeutic evaluation of various antibiotics from our case studies we could observe that the most frequently prescribed antibiotics are higher percentage of patients using Cephalosporins (51.14\%) followed by Macrolides (17.09\%), Metronidazole (12.58\%), Penicillin's (7.66\%), Aminoglycosides (3.41\%), Doxycycline $(3.41 \%)$, Fluoroquinolones (3.27\%), Carbapenems (1.30\%) as shown in fig 10.

- In our study 335 patients among them 153 patients are diagnosed with Pulmonary Tuberculosis. So they are using ATT Category-I and Category-II drugs respectively as shown in table 11.

\section{CONCLUSION}

LRTI usually causes minor illness, but may result in significant morbidity and mortality. Better lay and professional awareness of the often prolonged course of LRTI may improve understanding and appropriate use of antibiotics. In this study the Health care professionals are increase the awareness for improving quality of life in critically ill LRTIs patients and preventing further complications.

\section{ACKNOWLEDGEMENT}

The authors wish to thank all the staff members and nurses of the Government fever hospital, Guntur, for their invaluable contribution to the publication of this paper as a result of their outstanding daily bedside work. The authors declare no competing interests.

\section{REFERENCES}

1. Bronchitis from the internet https://www.mayoclinic.org/diseaseconditions/bronchitis/symptoms-causes/syc-20355566

2. Bronchiolitis from the internet https://www.mayoclinic.org/diseaseconditions/bronchiolitis/symptoms-causes/syc-20351565.

3. Barbara G. Wells, Joseph T.Dipiro, Terry L. Schwinghammer Cecily V. Dipiro: Pharmacotherapy Handbook $9^{\text {th }}$ Edition; Page no 835.

4. McLuckie, A.,ed(2009)Respiratory diseases and its management. New york: springer P51.ISBN 978-1-84882-094-4. 
5. Leach, Richard E (2009) Acute and critical care medicine at a Glance $\left(2^{\text {nd }}\right.$ ed $)$ WileyBlackwell. ISBN 1-4051-6139-6.

6. Pneumonia; Definition, Types of pneumonia, Types by location,

7. Types by how they are acquired- Health Line. https://www.Health.com/health/pneumonia\#types,location,acquired.

8. NADIA AIT-KHALED, DONALD A.ENARSON: Tuberculosis a manual for medical students, page no:3-35.

9. Macfarlane J, Holmes W, Macfarlane R, Do hospital physicians have a role in reducing antibiotic prescribing in the community? Thorax 2000; vol55, page no 153-158.

10. Mike Thomas, The management of acute lower respiratory tract infection in adults in primary care;2000 vol9, page no 4-7. 